\title{
Koroner arter ektazisi olan hastalarda plazma viskozitesi
}

\author{
Plasma viscosity in patients with coronary artery ectasia \\ Halil Bilgili, Bahar Öztürk*, Semra Özdemir, Ertan Yetkin
}

Kardiyoloji Kliniği (Dr. H. Bilgili), Polatlı Duatepe Devlet Hastanesi, TR-06900 Ankara, Biyofizik Anabilim Dalı (Arş. Gör. B. Öztürk, Prof. Dr. S. Özdemir), İstanbul Üniversitesi Cerrahpaşa Tıp Fakültesi, TR-34098 İstanbul, Kardiyoloji Kliniği (Prof. Dr. E. Yetkin), Özel Mersin Ortadoğu Hastanesi, TR-33340 Mersin

\section{Özet}

Amaç. Koroner arter ektazisi (CAE) koroner arterlerdeki lokalize veya yaygın anevrizmatik genişlemeler olarak tanımlanır. Plazma viskozitesi fibrinojen, immünoglobülinler ve lipoproteinler gibi çeşitli makromoleküller tarafından belirlenir. Bu nedenle kardiyovasküler hastalıklarda klasik risk faktörleri, hemostatik bozukluklar ve enflamasyon etkilerini çeşitli açılardan yansıtabilir. Çalışmada koroner arter hastalığında (KAH) risk faktörü olarak kabul edilen plazma viskozitesinin, koroner arter ektazili hastalarda bir farklılık gösterip göstermediğini incelemeyi amaçladık. Yöntem. Çalışmaya rutin koroner anjiyografiler sırasında koroner arter ektazisi (24 hasta) ve koroner arter hastalığı (24 hasta) tespit edilen hastalar alındı. Hastaların yaş, cinsiyet, diyabet varlığı, hipertansiyon, tütün içiciliği gibi kardiyovasküler risk faktörleri ve aldığı tedaviler sorgulandı. Tüm hastaların plazma viskozite düzeyleri ölçüldü ve istatistiksel olarak karşılaştırıldı. Bulgular. Plazma viskozitesi KAH'lı grupta 1,19 $\pm 0,70 \mathrm{mPa} \cdot \mathrm{s}$, KAE'li grupta 1,18 $\pm 0,80 \mathrm{mPa} \cdot \mathrm{s}$ olarak ölçüldü. Her iki grup arasında istatistiksel olarak anlamlı fark bulunamadı $(\mathrm{p}>0,05)$. Sonuç. Plazma viskozitesinin kardiyovasküler risk faktörü olmakla birlikte, KAE hastalığ fizyopatolojisinde, nedensel bir rol oynamadığı söylenebilir. Fibrinojen seviyelerinde gruplar arası değişiklik saptanmaması viskozite değerleri bulgularımızı desteklemektedir.

Anahtar sözcükler: Koroner arter ektazisi, koroner arter hastalığı, plazma viskozitesi

\begin{abstract}
Aim. Coronary artery ectasia (CAE) is defined as localized or generalized aneurysmal dilatation of the coronary arteries. Plasma viscosity is determined by various macromolecules, eg, fibrinogen, immunoglobulins, and lipoproteins. It may therefore reflect several aspects involved in cardiovascular diseases, including the effects of classic risk factors, hemostatic disturbances, and inflammation.In this study we aimed to observe plasma viscosity of the patients with coronary artery ectasy, which is a important risk factor in coronary artery disease (CAD). In our study, viscosity of the plasma has been calculated. Method. 24 coronary artery ectasy patients and 24 coronary artery disease patients have included the study. Age, sex, cardiovascular risk factors such as existence of hypertension, smoking history and previous medication have been investigated. Plasma viscosity of all patients have been measured. Results. Plasma viscosity of coronary artery disease patients group was measured as $1.19 \pm 0.7 \mathrm{mPa} \cdot \mathrm{s}$, coronary artery ectasy patients group was measured as $1.18 \pm 0.8 \mathrm{mPa} \cdot \mathrm{s}$. There was no statistically significant difference between two groups $(\mathrm{p}>0.05)$. Conclusion. However plasma viscosity is a good known cardiovascular risk factor, one can say it does not play causal role in coronary artery ectasy. As expected there is no diffrence on fibrinogen levels between the groups, this result supports our findings on the viscosity values.
\end{abstract}

Keywords: Coronary artery ectasy, coronary artery disease, plasma viscosity

Geliş tarihi/Received: 28 Haziran 2013; Kabul tarihi/Accepted: 16 Temmuz 2014

*İletişim adresi:

Dr. Bahar Öztürk, Biyofizik Anabilim Dalı, İstanbul Üniversitesi Cerrahpaşa Tıp Fakültesi, TR34098 İstanbul. E-posta: bhroztrk@istanbul.edu.tr 
Bu çalışma; 13-17 Eylül 2011 tarihleri arasında Edirne'de yapılan 23. Ulusal Biyofizik Kongresi’nde sözlü bildiri olarak sunulmuştur.

\section{Giriş}

Koroner arter ektazisi, doğuştan ya da kazanılmış koroner anomali olup epikardiyal koroner arterin bir bölümünün veya tamamının, lokalize ya da yaygın olarak komşu normal koroner arter çapından 1,5 kattan daha fazla genişlemesidir [1-5]. Koroner kalp hastalığı dünya ile paralel olarak ülkemizde de önemli mortalite ve morbidite nedenidir [6]. Yapılan farklı çalışmalarda sıklığı \%0,3-10 olarak tespit edilmiştir [1, 7-9]. Etiyolojide, hastaların \%50-60'ında ateroskleroz, \%20-30' da konjenital nedenler, \%10-20 kadarında da enflamatuar veya bağ doku hastalıkları olduğu ileri sürülmektedir [3].

Koroner damarların özellikle dallanma bölgelerinde subintimal yerleşimli aterom plakları bir yandan lümeni daraltırken öte yandan da kanın akış hızı ve şeklinde değişikliklere neden olmaktadır. Bunun yanında endotel ve trombosit kökenli çeşitli lokal ve metabolik faktörler de kanın akışkanlığında değişikliklere yol açmaktadır.

Hagen-Poiseuille yasasına göre, laminar akım koşullarında akım direnci, damarın geometrik özelliklerinden (damar çapı ve uzunluğu) kaynaklanan damar direncine ve sıvının akıma karşı gösterdiği dirence yani viskozitesine bağlıdır. Doku perfüzyonunun sağlanmasında basınç farkını oluşturan kalbin pompa kuvveti ve akım direncine katkıda bulunan damar geometrisi kadar akışkanlık özellikleri de son derece önemlidir [10].

Plazma viskozitesi (PV), plazmanın ana maddesi olan suyun ve onun içinde erimiş olan makromoleküllerin özelliklerine bağlıdır. Makromoleküllerin varlığı suyun akıma karşı gösterdiği direnci, yani viskozitesini artırır. $\mathrm{Bu}$ nedenle plazmanın viskozitesi suya göreceli olarak da ifade edilir. Plazma viskozitesinin $37^{\circ} \mathrm{C}$ 'deki normal değeri, aynı sicaklıktaki suyun viskozitesinin 1,4-1,8 katıdır. Proteinlerin plazma viskozitesine etkileri yoğunluklarına, kütlelerine ve şekillerine göre değişir [11].

PV birçok epidemiyolojik çalışmada kardiyovasküler risk göstergesi olarak belirtilmiş olup ilk ve tekrarlayıcı kardiyak olayların ve bunlara bağlı mortalitenin bağımsız habercisi olarak gösterilmiştir. PV obezite, diyabet, hipertansiyon, sigara içimi ve hiperlipidemi gibi geleneksel kardiyovasküler risk faktörlerinden de etkilenir ve plazma lipitleri ile benzer prediktif değere sahiptir [12].

PV aynı zamanda plazma lipit konsantrasyonuyla da ilişkilidir [13]. Arterlerde, trombositce zengin plazma, damar duvarı yakınlarında akarken eritrositler merkezde toplanmaktadırlar. PV paraproteinemi durumunda şiddetli olarak arttığında bir hiperviskozite sendromu sıkça görülmektedir [14]. Genelde PV seviyesi, hastalık süreçleri için spesifik olmayan iyi bir indikatördür ve akut faz reaksiyonlarıyla ilgili patofizyolojik şartlarda plazma protein içeriğiyle ilişkili olarak artar [15].

$\mathrm{Bu}$ çalışmada koroner arter hastalığında $(\mathrm{KAH})$ risk faktörü olarak kabul edilen plazma viskozitesinin koroner arter ektazili hastalarda bir farklılık gösterip göstermediğini incelemeyi amaçladık.

\section{Gereç ve yöntem}

Çalışmaya, Abant İzzet Baysal Üniversitesi İzzet Baysal Tıp Fakültesi Kardiyoloji Anabilim Dalı'nda yapılan rutin koroner anjiyografiler sirasında koroner arter ektazisi ve koroner arter hastalığı tespit edilen hastalar dahil edildi. Kontrol grubu, rutin koroner anjiyografi sirasinda KAH'lı (en az bir epikardiyal koroner arterde $\geq \% 50$ darlık olan) tespit edilen 24 hastadan; çalışma grubu ise koroner anjiyografiler sırasında koroner arter ektazisi tespit edilen 24 hastadan oluşturuldu. Çalışma ve kontrol gruplarında oral antikoagülan kullanan hastalar, hematolojik (Polisitemia vera, esansiyel trombositemi, trombositozlar, kronik hastalık anemisi, heparin ilişkili trombositopeni, talasemi vb.) veya onkolojik hastalık tanısı olanlar, renal ve hepatolojik hastalık tanısı olanlar, atriyal fibrilasyonu olan, akut koroner sendrom tanis1 alan hastalar, akut enfeksiyonu veya 
bilinen kronik sistemik hastalığ olan hastalar (Romatoid artrit, otoimmün hastalıklar vb.) çalışma dışında bırakıldı. Hastalara çalışma ayrıntılı olarak anlatıldı ve çalışmayı kabul ettiklerine dair onam alındı. Tüm hastalar hipertansiyon, hiperlipidemi, diyabet, tütün içiciliği, geçirilmiş miyokard infarktüsü, KAH aile hikayesi ve kullandığı ilaçlar yönünden ayrıntılı olarak sorgulandı. KAH Aile hikayesi birinci derece yakınlarında erkek için $<55$ yaş, kadın için $<65$ yaş olarak kabul edildi. Hastaların kilo ve boy ölçümleri alındı. Vücut kitle indeksi (VKİ) ve vücut yüzey alanı (BSA) hesaplandı. Hiperlipidemi öyküsü, antihiperlipidemik tedavi alması ya da herhangi bir zamanda bakılan açlık lipit profilinin LDL $>160 \mathrm{mg} / \mathrm{dL}$ veya total kolesterol $>240 \mathrm{mg} / \mathrm{dL}$ veya trigliserid $>160 \mathrm{mg} / \mathrm{dL}$ tespit edilmesi olarak kabul edildi. Hastalar 30 dakika öncesinde kafeinli içecek ve sigara içmemeleri koşuluyla 15 dakika sessiz ortamda dinlendirilerek sistolik ve diyastolik tansiyonları ölçüldü. Elde edilen kan basınçları sonucu 3 farklı ölçümde $>140 / 90$ olanlar veya antihipertansif kullananlar hipertansif olarak kabul edildi. Her iki hasta grubunda da rutin hemogram ve biyokimya tetkikleri yapıldı. Hastaların hemoglobin (Hgb), hematokrit (Hct), trombosit sayısina (Plt), ortalama platelet hacmine (Mpv), karaciğer fonksiyon testlerine, renal fonksiyon testlerine, total protein, albümin ve fibrinojen değerlerine bakıldı. Hastaların koroner anjiyografileri Siemens Axiom Artis cihazı ile yapıldı. Anjiyografi femoral arter ponksiyonu ile standart $6 \mathrm{~F}$ Judkins sağ ve sol kateterler kullanılarak yapıldı. Radyoopak olarak iodixanol veya iohexol kullanıldı. Sol koroner sistem için en az 4, sağ koroner sistem için en az 2 projeksiyonda görüntü alınıp dijital hafızaya kaydedildi. Koroner anjiyografi için kliniğe yatırılan hastalardan işlem öncesi rutin hemogram ve biyokimya tetkikleri için venöz yoldan kan alındı. PV ölçümü için alınan kan örneklerinden elde edilen plazma $-80{ }^{\circ} \mathrm{C}$ 'de saklandı. Viskozite ölçümleri Harkness Viskozimetresi (Coulter Electronics LTD, İngiltere) ile İstanbul Üniversitesi Cerrahpaşa Tıp Fakültesi Biyofizik Anabilim Dalı'nda gerçekleştirildi.

\section{Ístatistiksel analiz}

Çalışmanın istatistiksel analizleri SPSS sürüm 16 istatistik (SPSS for Windows 16, Inc, Chicago, IL, USA) programı kullanılarak yapıldı. Veriler yüzde ve aritmetik ortalama \pm standart deviasyon şeklinde sunuldu. Birbirinden bağımsız ve nonparametrik iki grubun karşılaştırmasında Mann-Whitney-U testi kullanıldı. Bütün analizlerde anlamlılık sınırı olarak $\mathrm{p}<0,05$ olarak kabul edildi.

\section{Bulgular}

Çalışmaya alınan hasta grupları arasında ortalama yaş, cinsiyet, boy, kilo, vücut kitle indeksi ve vücut yüzey alanı bakımından istatistiksel fark saptanmadı ( $>0,05)$. KAH'lı grupta 7, KAE'li grupta 5 hastada aile öyküsü pozitifti. Tütün içiciliği ve hipertansiyon açısından her iki grup arasında istatistiksel olarak fark yoktu ( $>0,05)$ (Tablo 1). Rbc, $\mathrm{Hgb}, \mathrm{Htc}, \mathrm{Plt}, \mathrm{Mpv}$ değerleri ile plazma viskozitesinin değerlendirilmesinde anlamlı olan total protein, albümin ve fibrinojen değerleri karşılaştırıldı. Gruplar arasında istatistiksel açıdan anlamlı fark bulunamadı ( $>0,05)$ (Tablo 2).

Tablo 1. Hastaların demografik özellikleri.

\begin{tabular}{llll}
\hline Değişkenler & KAH $(\mathbf{n = 2 4})$ & KAE $(\mathbf{n = 2 4})$ & p değeri \\
\hline Yaş (y1l) & $65 \pm 10$ & $63 \pm 10$ & 0,594 \\
Erkek cinsiyet & $\% 62,5(15)$ & $\% 70,8(17)$ & 0,545 \\
Aile öyküsü & $\% 29(7)$ & $\% 20,8(5)$ & 0,509 \\
Tütün içiciliği & $\% 50(12)$ & $\% 58(14)$ & 0,566 \\
Hipertansiyon & $\% 91,7(22)$ & $\% 75(18)$ & 0,125 \\
Diyabet & $\% 50(12)$ & $\% 25(6)$ & 0,580 \\
Boy $(\mathrm{cm})$ & $168,29 \pm 5,782$ & $170,58 \pm 5,413$ & 0,192 \\
Kilo $(\mathrm{kg})$ & $79,13 \pm 11,509$ & $77,54 \pm 10,1$ & 0,157 \\
VKİ $\left(\mathrm{kg} / \mathrm{m}^{2}\right)$ & $27,6 \pm 4,11$ & $26,4 \pm 3,19$ & 0,097 \\
BSA $\left(\mathrm{m}^{2}\right)$ & $1,90 \pm 0,12$ & $1,89 \pm 0,11$ & 0,252 \\
\hline
\end{tabular}


Tablo 2. Çalışma gruplarına ait laboratuvar değerleri.

\begin{tabular}{llll}
\hline Değişkenler & KAH $(\mathbf{n = 2 4})$ & KAE $(\mathbf{n = 2 4})$ & p değeri \\
\hline Hgb $(\%)$ & $13,4 \pm 1,5$ & $13,2 \pm 1,6$ & 0,620 \\
MPV (fL) & $7,82 \pm 0,94$ & $7,86 \pm 1,27$ & 0,972 \\
Platelet $(\times 103 / \mu L)$ & $286 \pm 86$ & $242 \pm 64$ & 0,117 \\
Total kolesterol $(\mathrm{mg} / \mathrm{dL})$ & $192 \pm 44$ & $172 \pm 39$ & 0,160 \\
Trigliserid $(\mathrm{mg} / \mathrm{dL})$ & $154 \pm 98$ & $135 \pm 58$ & 0,883 \\
LDL $(\mathrm{mg} / \mathrm{dL})$ & $120 \pm 41$ & $109 \pm 30$ & 0,221 \\
HDL $(\mathrm{mg} / \mathrm{dL})$ & $38 \pm 10$ & $35 \pm 8$ & 0,315 \\
Üre $(\mathrm{mg} / \mathrm{dL})$ & $35 \pm 1,1$ & $39 \pm 1,2$ & 0,471 \\
Kreatinin $(\mathrm{mg} / \mathrm{dL})$ & $0,8 \pm 0,2$ & $0,7 \pm 0,1$ & 0,279 \\
Total protein $(\mathrm{mg} / \mathrm{dL})$ & $7,02 \pm 0,5$ & $6,8 \pm 0,5$ & 0,309 \\
Albümin $(\mathrm{g} / \mathrm{dL})$ & $4,1 \pm 0,36$ & $4,06 \pm 0,3$ & 0,103 \\
Fibrinojen (mg/dL) & $404 \pm 100$ & $391 \pm 113$ & 0,612 \\
Plazma viskozitesi (mPa.s) & $1,19 \pm 0,07$ & $1,18 \pm 0,07$ & 0,363 \\
\hline
\end{tabular}

\section{Tartışma}

Koroner arter ektazisi (KAE), nadir görülen, konjenital veya edinsel bir koroner arter patolojisidir. Genellikle koroner aterosklerozun bir varyantı olup, lokalize veya yaygın koroner dilatasyonları şeklinde görülmektedir. KAE, koroner kan akımında yavaşlamaya, türbülan akıma, trombüs ve endotel disfonksiyonuna neden olabilmektedir ve genellikle asemptomatiktir [16]. Bununla birlikte KAE patofizyolojisinde KAH'dan ayrilan ya da farklılık gösteren özelliklerinin bulunması, KAE patofizyolojisinde aterosklerozdan bağımsız süreçlerin daha etkili olabileceğini düşündürmektedir.

PV ve diğer hemoreolojik faktörler mikrosirkülasyonu düzenler. PV ve fibrinojen gibi parametreler inflamatuar ve neoplastik olaylarda da birer akut faz reaktanı olarak yükselebildiğinden, uluslararas1 rehberlere göre hemoreolojik faktörlerle ilgili çalışmalarda sağlıklı kontrol gruplarına ihtiyaç duyulmaktadır [17]. PV'nin belirlenmesinde, eritrosit agregasyonundan sorumlu olan fibrinojen, gama globülin ve plazma lipit konsantrasyonları başlıca rol almaktadır [13]. Fibrinojenin temel fizyolojik fonksiyonu, hemostazda fibrin ağı oluşumudur. Son çalışmalar fibrinojenin kardiyovasküler hastalıkların ve tromboembolik komplikasyonların habercisi olabileceğini göstermiştir [12]. Fibrinojen, immunoglobülin gibi akut faz reaktanları hastalık süreçlerinde PV'nin spesifik olmayan artışına neden olmaktadır [15]. Polistemi, hiperlipoproteinemi, hiperproteinemi, miyokard infarktüsü, diyabet, orak hücreli anemi, Waldenström makroglobulinemisi, paraproteinemi ve myelositer lösemi gibi birçok hastalıkta da PV artarken; anemi ve afibrinojenemi durumlarında azalmaktadır [18-21]. Kanın şekilsiz elamanlarının oluşturduğu plazmanın viskozitesi kanın akışkanlığı ve direncini gösteren önemli bir parametredir. Yüksek kan ve plazma viskozitesinin ateroskleroz oluşumuyla sonuçlanan etkileri olduğu; hatta genel kabul görmüş risk faktörlerine kıyasla ateroskleroz ile daha kuvvetli bir ilişkisi olduğu ileri sürülmüştür [22, 23]. KAE'de doku düzeyinde özellikle muskuloelastik yapılardaki değişiklikler dışında koroner kan akımının azaldığını gösteren çalışmalar vardır [24]. Anjiyografik opak maddenin koroner arterde yavaş ilerlemesi, verilen opak maddenin stagnasonu veya stazisi bunun göstergeleridir. Yine TIMI kare sayısı esas alınarak yapılan çalışmalarda KAE hastalarında yavaş akım varlığı gösterilmiştir [25]. KAE fizyopatolojisinde özellikle inflamatuar sürecin KAH olanlara göre daha yüksek olduğu saptanmıştır. Çalışmamızda inflamatuar parametre olarak fibrinojen değerlerinin benzer çıkması inflamatuar sürecin daha sessiz olması şeklinde açıklanabilir. Plazma viskozitesinde belirleyici olan plazma proteinlerinin ve özellikle fibrinojenin gruplar arasında farklılık göstermemesi azalmış koroner kan akımının plazma viskozitesi ile ilişkisi olmadığını düşündürmektedir. Bu sonuç KAE’de görülen yavaş kan akımının plazma içeriği ile ilgili değil daha çok damar vazomotor hareket regülasyonu ile ilgili olduğunu sonucuna varılabilir. Bu amaçla yapılan çalışmalarda da KAE olan hastalarda endotel bağımlı fonksiyonların KAH'lı olanlarla aynı düzeyde bozuk olmasına rağmen, endotelden bağımsız fonksiyonların yani mediya tabakasını gösteren vazodilatatör kapasitenin daha bozuk olduğu gösterilmiştir. 
Kan reolojisindeki değişikliklerin birçok hastalığın patofizyolojisinde tespit edilen önemi, bu konuda birçok çalışmanın esin kaynağı olmuştur. Çalışmamızın da bugüne kadar elde edilen bilgileri destekleyici ve bu alanda yeni fikirlerin oluşmasına yardımcı olmasını ümit etmekteyiz.

\section{Kaynaklar}

1. Yetkin E, Waltenberger J. Novel insights into an old controversy: is coronary artery ectasia a variant of coronary atherosclerosis? Clin Res Cardiol 2007; 96: 331-9.

2. Swaye PS, Fisher LD, Litwin P, Vignola PA, Judkins MP, Kemp HG, Mudd JG, Gosselin AJ. Aneurysmal coronary artery disease. Circulation 1983; 67: 134-8.

3. Falsetti HL, Carroll RJ. Coronary artery aneurysm. A review of the literature with a report of 11 new cases. Chest 1976; 69: 630-6.

4. Markis JE, Joffe CD, Cohn PF, Feen DJ, Herman MV, Gorlin R. Clinical significance of coronary arterial ectasia. Am J Cardiol 1976; 37: 217-22.

5. Maehara A, Mintz GS, Ahmed JM, Fuchs S, Castagna MT, Pichard AD, Satler LF, Waksman R, Suddath WO, Kent KM, Weissman NJ. An intravascular ultrasound classification of angiographic coronary artery aneurysms. Am J Cardiol 2001; 88: 365-70.

6. Türkiye Kalp Raporu 2000, Türk Kardiyoloji Derneği, Yenilik Basımevi, İstanbul 2000; 11-25.

7. Befeler B, Aranda MJ, Embi A, Mullin FL, El-Sherif N, Lazzara R. Coronary artery aneurysms: Study of their etiology, clinical course and effect on left ventricular function and prognosis. Am J Med 1977; 62: 597-607.

8. Oliveros RA, Falsetti HL, Carroll RJ, Heinle RA, Ryan GF. Atherosclerotic coronary artery aneurysm: report of five cases and review of literature. Arch Intern Med 1974; 134: 1072-6.

9. Hartnell GG, Parnell BM, Pridie RB. Coronary artery ectasia. Its prevalence and clinical significance in 4993 patients. Br Heart J 1985; 54: 392-5.

10. Demir E. Koroner yavaş akımlı hastaların hemoreolojik parametrelerinin değerlendirilmesi. Pamukkale Üniversitesi Tıp Fakültesi, Kardiyoloji Anabilim Dalı, Uzmanlık Tezi, Denizli 2011.

11. Dikmenoğlu N. Kardiyovasküler hastalıklarda sigara ve kolesterol kadar önemli bir risk faktörü: kan akışkanlığı. Hacettepe Tıp Dergisi 2006; 37: 93-7.

12. Yolcu M, Bilgili H, Küçükdurmaz Z, Karapınar H, Dokumacı B. Koroner arter hastalığ1 yaygınlığı ile plazma vizkositesi ve fibrinojen düzeyleri arasındaki ilişki. Türk Göğüs Kalp Damar Cerrahisi Dergisi 2012; 16: 15-9.

13. Gapinska, AM, Jaroszyk, F, Elikowski W, Kubisz, L. The effect of acetylsalicylic acid and acenocoumarin on rheological properties of blood studied on patients after myocardial infarction. Current Topics in Biophysics 2004; 28: 3-8.

14. Reinhart, WH. Hemorheology: blood flow hematology. Schweiz Med Woochenschr 1995; 125: 387-95.

15. Baskurt OK. Rheologic properties of blood. Doğa-Tr.J.of Medical Sciences 1990; 14: 433-7.

16. Altıparmak İH, Kaya Z, Sezen H, Aydın MS, Demirbağ R, Aksoy N. Serum paraoksonaz-1 aktivitesinin izole koroner arter ektazisi ile ilişkisi: Gözlemsel bir çalışma. Anadolu Kardiyoloji Dergisi 2012; 12: 307-12.

17. Baskurt OK, Boynard M, Cokelet GC, Connes P, Cooke BM, Forconi S, Liao F, Hardeman MR, Friedrich Jung F, Meiselman HJ, Nash G, Nemeth N, Neu B, Sandhagen B, Shin S, Thurston G, Wautier JL. New guidelines for hemorheological laboratory techniques. Clin Hemorheol Microcirc 2009; 42: 7597.

18. Leonhardt $\mathrm{H}$, Bungert HJ. Plasma viskositat und portale hypertension bei bercirrhosekranken. Klın Wschr 1973; 51: 1043-49.

19. Ernst E, Matrai A, Schmölzl CH, Magyarosy I. Dose-effect relationship between 
smoking and blood rheology. Br J Haematol 1987; 65: 485-7.

20. Ernst E, Schmid WM, Baumann M, Matrai A. Cardiovascular risk factors and hemoreology. Atherosclerosis 1986; 59: 263-9.

21. Solerto SB, Fioravanti M, Patti AL, Fedele P, Ferrari E. Incresed plasmaapolipoprotein B levels and blood hyperviscosity in noninsülin dependent diabetic patients: Role in the occurence of arterial hypertension. Acta Diabetol Lal 1987; 24: 341-9.

22. Kensey KR. The mechanistic relationships between hemorheological characteristics and cardiovascular disease. Curr Med Res Opin 2003; 19: 587-96.

23. Lee AJ, Mowbray PI, Lowe GDO, Rumley A, Fowkes FGR, Allan PL. Blood viscosity and elevated carotid intima-media thickness in men and women:the Edinburgh Artery Study. Circulation 1998; 97: 1467-73.

24. Chrissoheris MP, Donohue TJ, Young RS, Ghantous A. Coronary Artery Aneurysms. Cardiol in Rev 2008; 16: 116-23.

25. Papadakis MC, Manginas A, Cotileas P, Demopoulos V, Voudris V, Pavlides G, Foussas SG, Cokkinos DV. Documentation of slow coronary flow by the TIMI frame count in patients with coronary ectasia. Am J Cardiol 2001; 88: 1030-2. 